\title{
Benefits of Expressive Writing on Healthcare Workers' Psychological Adjustment During the COVID-19 Pandemic
}

OPEN ACCESS

Edited by:

Elena Vegni,

University of Milan, Italy

Reviewed by:

Andrea Sabrina Hartmann, University of Osnabrück, Germany Giorgia Margherita, University of Naples Federico II, Italy

*Correspondence:

Rossella Procaccia

rossella.procaccia@uniecampus.it

Specialty section:

This article was submitted to Psychology for Clinical Settings, a section of the journal

Frontiers in Psychology

Received: 30 October 2020

Accepted: 26 January 2021

Published: 25 February 2021

Citation:

Procaccia R, Segre G, Tamanza G and Manzoni GM (2021) Benefits of Expressive Writing on Healthcare Workers' Psychological Adjustment

During the COVID-19 Pandemic.

Front. Psychol. 12:624176.

doi: 10.3389/fpsyg.2021.624176

\section{Rossella Procaccia ${ }^{1 *}$, Giulia Segre1, Giancarlo Tamanza² and Gian Mauro Manzoni1 \\ ${ }^{1}$ Faculty of Psychology, eCampus University, Novedrate, Italy, ${ }^{2}$ Department of Psychology, Catholic University of Milan, Milan, Italy}

COVID-19 outbroke in Wuhan, China, in December 2019 and promptly became a pandemic worldwide, endangering health and life but also causing mild-to-severe psychological distress to lots of people, including healthcare workers (HCWs). Several studies have already showed a high prevalence of depression, anxiety, and posttraumatic symptoms in HCWs but less is known about the efficacy of psychological interventions for relieving their mental distress. The aims of this study were: (1) to evaluate the psychological adjustment of Italian HCWs during the COVID-19 pandemic; (2) to investigate the efficacy of an expressive writing (EW) intervention, based on Pennebaker's paradigmatic protocol, on their psychological adjustment; (3) to analyze if outcomes of EW vary in function of individual differences (age, gender, marital status, and baseline values of symptoms). Fifty-five HCWs were randomly assigned to one of two writing conditions: EW ( $n=30$ ) or neutral writing (NW; $n=25)$. Psychological adjustment (in terms of ptsd, depression and global psychopathology's symptoms, perceived social support, and resilience) was assessed before and after three writing sessions. Participants who received the EW intervention showed higher improvements in ptsd, depression, and global psychopathology symptoms. Improvements in EW group varied in function of age, gender, marital status, and baseline values: young, men, married participants and those who had higher baseline scores showed a higher reduction of psychological distress symptoms while women, single and those who had lower baseline value showed increased social support, and resilience. In conclusion, the EW intervention had positive effects which varied in function of individual differences on HCWs' psychological health.

Keywords: COVID-19, healthcare workers, psychological adjustment, expressive writing, distress

\section{INTRODUCTION}

Since December 2019, a pneumonia epidemic caused by the 2019 novel coronavirus (SARS-COV2) outbroke in Wuhan and spread across China rapidly; it became a global pandemic within the following 2 months [World Health Organization (WHO), 2020]. Italy was, after China, the second in time country most affected by the COVID-19 outbreak. 
Although higher levels of psychological distress have been reported among the general population (Serafini et al., 2020), healthcare professionals, given their crucial role in managing these emergency situations, seem to be more vulnerable. Overall, pandemic requires intense and prompt responses in terms of healthcare: healthcare workers (HCWs), either directly or indirectly, are involved in delivering care to patients, fighting at the frontline against the virus. Medical staff and affiliated HCWs are under both physical and psychological pressures. Considering that, at a normal time, nearly half of physicians report burnout, or emotional burden due to work-related stress (West et al., 2018), supporting their mental health in such an overwhelming COVID-19 sanitary emergency is a critical part of the public health response.

Self-reported psychological problems are prevalent in HCWs during the COVID-19 pandemic. A recent review (Preti et al., 2020) analyzed the effects of epidemic and pandemic outbreaks on HCW's mental health: anxiety (45\%), depression (27.5-50.7\%), general psychiatric symptoms (17.3-75.3\%), posttraumatic stress disorder (11-73.4\%), insomnia (34-36.1\%), and work-related stress symptoms $(18.1-80.1 \%)$ are the most common symptoms. In particular, it has been stated that female healthcare professionals and nurses exhibited higher rates of affective symptoms compared to male and medical staff, respectively (Pappa et al., 2020).

Moreover, Chew et al. (2020) demonstrated a possible bidirectional association between the physical and psychological symptoms among HCWs during the COVID-19: timely psychological interventions for HCWs with physical symptoms should be considered, once an infection has been excluded.

Healthcare workers should be aware of the early signs of mental fatigue, avoiding those to affect their emotional wellbeing. Recent studies (Kinman et al., 2020; Polizzi et al., 2020) have shown the importance of individual coping strategies: acceptance, behavioral activation and mindfulness could foster resilience and recovery by increasing tolerance to distress, enhancing feelings of connectedness and support, and encouraging actions that are goal-directed and value-driven. Reduced morbidity has been associated with both practical and psychological support (Kisely et al., 2020; Pappa et al., 2020). Less is known about interventions to mitigate the emotional impact of epidemics on HCWs (Gold, 2020). Health care professionals could benefit from different resources such as helplines, online therapy and group counseling sessions to reduce anxiety, distress, and insomnia symptoms.

Although evidence-based effective interventions and treatments in the healthcare system and among healthcare providers are available, stigma and lack of time limit their uptake, even in normal times (Knaak et al., 2017).

Many barriers limit the implementation of conventional evidence-based interventions in this emergency situation. Not all HCWs are willing to receive psychological treatment, individually or as a group therapy (Chen et al., 2020).

Secondly, traditional face-to-face psychotherapy is not recommended during quarantine, switching most of the therapies to remote sessions.
Moreover, another issue that has arisen is that during this emergency situation people tend to experience a wide range of mental health problems, while evidencebased interventions usually focus on a single disorder (Yang et al., 2020).

People particularly benefit from confiding about traumas (Vrij et al., 2002). Disclosing information may allow people to release their mind from unwanted thoughts, help them to make sense of upsetting events and improve their emotion regulation, all of which can have positive consequences on mental and physical health (Frattaroli, 2006).

Expressive writing (EW) is a simple and straightforward exercise. The reference model is based on Pennebaker (2004), which states that expressing deeper thoughts and feelings can alleviate the individual's physical and psychological health. Over the past 25 years (see Frattaroli, 2006; Pennebaker and Chung, 2007), several researchers have examined the effects of writing about traumatic life events. Pennebaker's EW task involves writing about a traumatic experience for a controlled period of time (usually between 15 and $30 \mathrm{~min}$ ), on consecutive days (usually from 2 to 4 days, Pennebaker, 1997). Although this technique has been compared to exposure-based therapies for posttraumatic stress disorder (Sloan et al., 2005, 2007), research on reducing posttraumatic stress symptoms through EW has shown inconsistent results (see Frisina et al., 2004). While some studies did not find strong links between posttraumatic stress symptoms and EW (Pennebaker and Chung, 2007), several studies have shown the benefits of writing across different sessions about personal experiences with stressful life-events. This procedure has been associated with the reduction of physical and mental symptoms both in clinical and normal simples (Pennebaker and Beall, 1986; Pennebaker and Francis, 1996; Smyth, 1998; Smyth et al., 1999). In addition, researchers have explored various individual difference indices to identify those subgroups for whom EW is most beneficial (Baikie and Wilhelm, 2005; Stickney, 2010). Smyth et al.'s (1999) meta-analysis found that it had a greater impact on males than on females. Results of other studies (Paez et al., 1999; Baikie, 2003; Solano et al., 2003) showed that EW is more beneficial for those high in alexithymia and high in dissociation. It is essential to understand the conditions under which EW works and how to maximize its benefits ( $\mathrm{Lu}$ and Stanton, 2010). A recent study found that EW positively impacted on HCW' adaptive coping strategies and work relational communication satisfaction. Similarly, EW was found to be a useful tool for nurses in high-stress areas: coping strategies are vital to fight against burnout and depression (Sexton et al., 2009).

Starting from these considerations, the first study hypothesis (H1) is that Italian HCWs have high levels of psychological distress during the COVID-19 pandemic. The second study hypothesis $(\mathrm{H} 2)$ is that the EW intervention is effective in reducing psychological distress in Italian HCWs. The third hypothesis (H3) is that the outcomes of the EW intervention vary in function of individual differences (age, gender, marital status, and baseline value). 


\section{MATERIALS AND METHODS}

\section{Study Design}

This study is a randomized and controlled trial with two conditions [EW vs neutral writing (NW)] and two repeated measurements (before and after the writing intervention).

\section{Participants}

One hundred HCWs who worked in two hospitals settled respectively, in middle and south Italy were asked to participate to the study.

To be included in the study healthcare professional have to work $24 \mathrm{~h}$ a week continuously for at least 6 months in the same hospital and they have to work from the pandemic outbreak in the frontline with COVID-19 patients, specifically in COVID19 Intensive Care Unit (ICU) or COVID-19 hospital ward. Professionals were excluded if they have been working in the same structure for shorter periods of time (less than 6 months), or were not directly working in COVID-19 wards.

Fifty-five out of them accepted to participate and were included in the study. Data were collected between April and June 2020. Participants were mainly females; the median age was 46.42 years old $(\mathrm{SD}=9.9)$ and the majority were married or cohabiting in a stable way. Nurses comprised more than half of the sample, followed by physicians and allied HCWs. Majority had a degree (Table $\mathbf{1}$ ).

\section{Procedure}

Participants were randomly assigned to one of two writing conditions: $\mathrm{EW}(n=30)$ or NW $(n=25)$. EW is a tool through which subjects describe their deepest thoughts and feelings about emotional events. NW is a comparison instrument, through which participants describe an event in a more objective way, without focusing on emotions, thoughts, or feelings (see Figure 1 for instruction).

TABLE 1 | Demographics.

\begin{tabular}{lcc}
\hline Total number & $\mathbf{5 5}$ & \\
\hline Occupational status & 30 & \\
Nurse & 15 & $54.54 \%$ \\
Physicians & 10 & $27.27 \%$ \\
Allied HCWs & & $18.18 \%$ \\
Gender & 14 & \\
Male & 41 & $25.45 \%$ \\
Female & & $74.54 \%$ \\
Marital status & 42 & \\
Married or cohabiting & 13 & $76.36 \%$ \\
Single & & $23.64 \%$ \\
Age (years) & $46.42(9.9)$ & \\
Mean (SD) & 28 & 61 \\
Min-max & & $56.36 \%$ \\
Education & 31 & $43.64 \%$ \\
Degree & 24 & \\
Post-graduate degree & & \\
& &
\end{tabular}

This study was carried out in keeping with the Ethics Code of Italian Psychologists and approved by the Ethics Committee of e Campus University. Informed written consent was obtained from participants. The data were handled in keeping with General Data Protection Regulation (GDPR), Regulation UE 2016/679. All participants received an envelope including the information about the aims of the study, consent forms, a socio-demographic questionnaire, and all the other study questionnaires (Time 1 ). They completed them individually at home and then they received another envelope with writing instructions. Three days after filling in those questionnaires, participants were asked to write at their home for three consecutive days for 20 min each time according to the two writing conditions and, after 1 week, they were asked to fill in again the study questionnaires (Time 2 ). Literature has shown contradictory results for the spacing of disclosure sessions. Smyth (1998) conducted a meta-analysis and showed larger effect sizes in studies with weekly disclosure sessions (7 days intervals between each writing session) than studies with daily sessions; number and length of writing sessions were unrelated to improvement. On the contrary, no significant differences between daily and weekly treatment groups were found in a study which manipulated the spacing of disclosure sessions (Frattaroli, unpublished). For what concerns the amount of time dedicated to writing sessions, it has been reported (Frattaroli, 2006) that writing for longer than $15 \mathrm{~min}$ is more effective. The present study followed the standard EW protocol, in which participants are usually asked to spend 15-30 min writing for three to five consecutive days (Pennebaker, 1997).

\section{Measures}

Demographic characteristics: Each participant was asked to indicate sex, age, marital/relationship status, level of education, years of practice, and role currently held.

The Beck Depression Inventory (BDI-II; Beck et al., 1996; Italian validation by Ghisi et al., 2006): The BDI-II was used to assess depressive symptoms. This measure includes 21 items, focused on cognitive, affective, motivational, and behavioral components of depression. For each item, this instrument uses a scale ranging from " 0 ," corresponding to a negative response (e.g., 0 = "I do not feel sad"), to "3," positive response. Items are summed up to yield a total score. Each item was scored on a four-point scale, with a total score of 63 . Based on the Italian validation, a cut-off score $\geq 12$ identified the presence or the absence of depression. Scores were categorized as 1319, mild depression; 20-28, moderate depression; and 29-63, severe depression. The Cronbach's $\alpha$ coefficient in normative or clinical samples has ranged from 0.80 to 0.87 (Beck et al., 1996). In this study, the $\alpha$ coefficient was respectively, 0.82 at Time 1 , and 0.83 at Time 2 .

Los Angeles Symptom Checklist (LASC; King et al., 1995). The LASC is a self-report instrument. It includes 43 items and measures overall global distress related to trauma exposure, overall PTSD symptomology severity, and PTSD symptoms on three subscales (re-experiencing, avoidance/numbing, and hyperarousal). The instrument was shown to possess high internal consistency with $\alpha$ coefficients ranging from 0.88 to 0.95 (King et al., 1995). In this research $\alpha$ coefficients were 0.92 


\begin{abstract}
Expressive writing instructions:
"Over the next three days, we would like you to write about your most profound thoughts and feelings about the stressful experiences you have had in your job during this time of pandemic emergency. It is very important that you describe the most secret thoughts and feelings that you have not said and that you would not tell anyone. Write for 20 consecutive minutes, without removing the pen from the paper. Do not worry about the grammar, spelling or structure of the writing. We would like, in your text, for you to examine your moods and deeper thoughts about this experience. It is essential that you let yourself go and come into contact with your emotions and deeper thoughts. You can write about different experiences during each session, or about the same experience for all three days. If you wish you can also talk about how you felt, of what you have thought and felt about your present, past or future life. The only rule is that once you start writing, continue until the end of 20 minutes for 3 consecutive days.".

Neutral writing instructions:

"We would like you to write for the next 3 days for 20 minutes continuously, without removing the pen from the paper, about what happened to you and what you did in this time of pandemic emergency. In this writing we would like you to be as objective as possible. We are not interested in your emotions or opinions. We want you to be completely objective. Feel free to be as detailed as possible. In today's writing we would like to describe what you did yesterday since you got up, until you went to bed. Do not worry about spelling, grammar, or sentence structure. The most important thing in this writing is to describe your days as accurately and objectively as possible. All the writings will be completely confidential. The only rule is that once you start writing, continue until the end of 20 minutes for 3 consecutive days".
\end{abstract}

FIGURE 1 | Expressive and neutral writing instructions.

(Time 1) and 0.93 (Time 2). That's there is not yet an Italian validation, LASC items were translated in Italian following back translation procedure.

Symptom Check List - 90 Revised (Derogatis, 1994; SCL90: Italian version by Prunas et al., 2012). The SCL-90R is a 90 question self-report inventory that is made up of 90 items on disorders that may have been tried in the last week. Subjects give a rating from 0 (not at all) to 4 (very much) on a Likert scale. Items converge in 10 symptomatic subscales of different significance (somatization, obsessive-compulsive disorder, interpersonal sensitivity, depression, anxiety, hostility, phobic anxiety, paranoid ideation, psychoticism, and sleep disturbances). For each scale, the relative score is calculated as the average of the answers. A global index is also calculated (GSIGlobal Score Index) as the average of all answers. Cronbach's $\alpha$ coefficients higher than 0.70 were considered acceptable (Peterson, 1994). In this study, the $\alpha$ coefficient was 0.97 at Time 1 and at Time 2 both.

Multidimensional Scale of Perceived Social Support (MSPSS; Zimet et al., 1988; Italian validation by Prezza and Principato, 2002). The MSPSS is a self-report instrument; it includes 12 items that converge in three dimensions: family, friends, and significant others. Each item is rated on a seven-point Likert-type response format ( 1 = very strongly disagree; 7 = very strongly agree). A total score is calculated by summing up all the answers. The possible score range is between 12 and 84, the higher the score the higher the perceived social support. The possible score range for the subscales/dimensions is between 4 and 28. Any mean scale score ranging from 1 to 2.9 could be considered low support; a score of 3-5 could be considered moderate support; a score from 5.1 to 7 could be considered high support. Cronbach's $\alpha$ coefficients range from 0.85 to 0.91 (Zimet et al., 1988). In this research $\alpha$ coefficients were 0.95 (Time 1 ) and 0.86 (Time 2).

Resilience Scale for Adult (RSA; Friborg et al., 2003; Italian validation by Di Fabio and Busoni, 2008). The RSA is a 33-items self-report instrument for evaluating six protective dimensions of resilience in adults: (1) perception of the self, (2) planned future, (3) social competence, (4) family cohesion, (5) social resources, and (6) structured style. Item-response ranges from one to seven and scores vary between 33 and 231, with higher scores indicating higher levels of resilience. Previous research showed Cronbach's $\alpha$ from 0.67 to 0.81 and total score 0.88 . In this study $\alpha$ coefficients were 0.87 at Time 1 and 0.89 at Time 2.

\section{Statistical Analysis}

Descriptive analysis was carried out computing baseline values for every variable, considering total score and subscales to include a wide range of distress dimensions.

Specifically, we analyzed ptsd (reexperiencing, avoidance, and hyperarousal), depression and global psychopathology's symptoms (Global Severity Index) (somatization, obsessivecompulsive disorder, interpersonal sensitivity, depression, anxiety, hostility, phobic anxiety, paranoid ideation, psychoticism, and sleep disturbances), perceived social support (significant other, family, and friend), and resilience.

Differently, since the small size of the sample, to improve the power of the statistics, we considered for hypothesis 2 and 3 only the total scores of each investigated variable (ptsd symptoms, 
depression symptoms, Global Severity Index, perceived social support, and resilience).

Repeated-measure ANOVAs were employed to test the effects of the EW intervention in comparison to NW on the study outcomes. All ANOVA models included a within-subject factor (pre scores and post scores), a between-subjects factor (EW vs NW) and their interaction, which was probed by means of plots in case of statistical significance. All ANOVA models also included the baseline value as a covariate variable, to control the effects of any significant differences in scores between EW and NW groups in pre-writing time.

Finally, delta values $(\Delta)$ were computed for the total scores as differences between pre-scores and post-scores, and were then regressed in EW group on age, gender (male-female), marital status (unmarried vs married or cohabiting), and baseline values in hierarchical multiple regression models. The SPSS 21 software was used.

\section{RESULTS}

\section{Psychological Conditions of Italian HCWs During the COVID-19 Pandemic}

Baseline descriptive statistics (Table 2) show a high level of PTSD according to the LASC cut-off for the PTSD Severity Index (see King et al., 1995, p. 14) as well as high symptoms of hyperarousal, avoidance, and reexperiencing. A high level of psychopathology was also observed on the SCL 90R Global Severity Index, which resulted to be higher than the suggested cut-off ( $T$ value $\geq 63$; Derogatis, 1994). In particular, high scores were found in the somatization, depression, obsessive-compulsive disorder, anxiety, sleep disturbances, and interpersonal sensitivity scales, while lower scores were found in the phobic anxiety, paranoid ideation psychoticism and hostility scales. With respect to depression symptoms assessed through the BDI II (Table 3), $45.45 \%$ of participants were in the minimal range, $32.73 \%$ in the mild depression range, $10.91 \%$ in the moderate depression range and $10.91 \%$ in the severe depression range. Participants perceived a moderate level of total social support according to Zimet et al. (1988). In sub-scales, high levels of perceived support from significant others and from family were observed, while a moderate level of perceived support from friends was found. Finally, they showed moderate level of resilience, according to Di Fabio and Busoni (2008).

\section{The EW Effects}

Statistically significant interaction effects were found for ptsd symptoms, depression symptoms, and Global Severity Index. No effects for social support and resilience were found (see Figure 2 and Table 4).

Plots showed that: (1) ptsd symptoms reduced significatively only in EW group (ptsd $\times$ writing condition $F=13.725$, $p=0.002$ ) (2) depression symptoms reduced in EW group while it increased in NW group (depression $\times$ writing condition: $F=6.123, p=0.02$ ); (3) the SCL-90R Global Severity Index reduced in EW group, while it increased in the NW group $(\mathrm{GSI} \times$ writing condition: $F=5.232 ; p=0.03)$.
TABLE 2 | Baseline descriptive statistics of psychological variables in the whole samples.

\begin{tabular}{|c|c|c|c|c|c|}
\hline Variable & $N$ & Mean & $\begin{array}{l}\text { Standard } \\
\text { deviation }\end{array}$ & Minimum & Maximum \\
\hline Reexperiencing & 55 & 4.04 & 2.08 & 1 & 7 \\
\hline Avoidance & 55 & 5.4 & 2.22 & 3 & 10 \\
\hline Hyperarousal & 55 & 11.53 & 5.34 & 5 & 23 \\
\hline Ptsd & 55 & 20.96 & 7.97 & 10 & 36 \\
\hline Depression (BDI-II) & 55 & 16.36 & 9.78 & 5 & 45 \\
\hline Somatization & 55 & 15.84 & 9.78 & 1 & 37 \\
\hline Obsessive-compulsive disorder & 55 & 10.33 & 8.11 & 1 & 28 \\
\hline Interpersonal sensitivity & 55 & 4 & 2.61 & 0 & 9 \\
\hline Depression (SCL90R) & 55 & 14.84 & 10.23 & 4 & 35 \\
\hline Anxiety & 55 & 9.67 & 9.91 & 2 & 31 \\
\hline Hostility & 55 & 2.33 & 1.93 & 0 & 7 \\
\hline Phobic anxiety & 55 & 3.56 & 5.88 & 0 & 17 \\
\hline Paranoid ideation & 55 & 3.47 & 2.38 & 0 & 10 \\
\hline Psychoticism & 55 & 3.18 & 2.69 & 0 & 12 \\
\hline Sleep disturbances & 55 & 5.58 & 4.49 & 0 & 12 \\
\hline GSI & 55 & 75.13 & 51.42 & 19 & 172 \\
\hline Significant others & 55 & 5.14 & 1.14 & 1 & 6 \\
\hline Family & 55 & 5.09 & 0.90 & 1 & 6 \\
\hline Friend & 55 & 3.98 & 0.93 & 1 & 6 \\
\hline Support & 55 & 4.74 & 0.89 & 1 & 6 \\
\hline Resilience & 551 & 116.29 & 10.53 & 95 & 144 \\
\hline
\end{tabular}

TABLE 3 | Depression scores distribution.

\begin{tabular}{lcc}
\hline Depression level & N & Frequency percent \\
\hline Minimal range & 25 & 45.45 \\
Mild depression & 18 & 32.73 \\
Moderate depression & 6 & 10.91 \\
Severe depression & 6 & 10.91 \\
\hline
\end{tabular}

\section{Predictors of Changes}

Multiple regression analyses were then performed in the EW group with $\Delta$ values of ptsd symptoms, depression symptoms, Global Index Severity, perceived social support, and resilience entered as dependent variables and age, gender, marital status, and baseline values as predictors. Results (Table 5) show that change in ptsd symptoms is predicted firstly by marital status and then by baseline value. In particular, married participants and the ones who presented higher levels of ptsd symptoms before writing sessions showed a higher improvement in post-traumatic reaction after EW.

Depression symptoms were predicted by marital status and age. Young and married participants' depression levels improved more after the writing intervention.

Age, gender, and baseline value predicted change in global psychopathology, with young, men and those who showed higher GSI score at baseline had higher improvements after EW.

Social support is predicted by gender, marital status, and baseline value: women, single and the ones who presented lower levels of perceived social support before writing sessions showed a higher improvement. In the same direction, resilience 


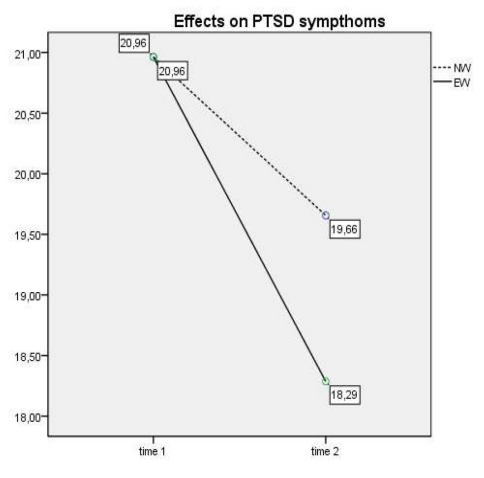

The covariates were calculated on base line value of ptsd $=20,96$

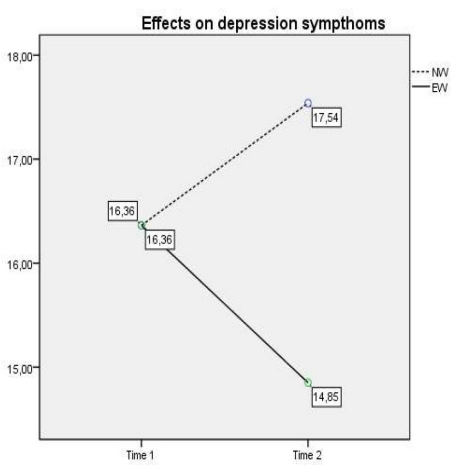

The covariates were calculated on baseline value of depression sympthoms $=16,36$

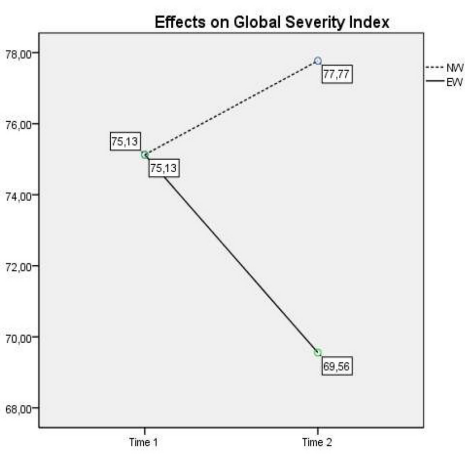

The covariates were calculated on baseline value of $\mathrm{GS}=75,13$

FIGURE 2 | Graphs of repeated-measure ANOVAs.

TABLE 4 | Repeated-measure ANOVAs.

\begin{tabular}{|c|c|c|c|c|c|}
\hline & $\begin{array}{l}\text { Sum of } \\
\text { square }\end{array}$ & df & $\begin{array}{l}\text { Mean } \\
\text { square }\end{array}$ & $\boldsymbol{F}$ & $p$ \\
\hline ptsd & 1.553 & 1 & 1.553 & 0.282 & 0.598 \\
\hline Ptsd $\times$ ptsd effect & 6.779 & 1 & 6.779 & 1.231 & 0.272 \\
\hline $\begin{array}{l}\text { Ptsd } \times \text { writing } \\
\text { condition }\end{array}$ & 12.777 & 1 & 12.777 & 13.725 & 0.002 \\
\hline Depression & 3.106 & 1 & 3.106 & 0.412 & 0.521 \\
\hline $\begin{array}{l}\text { Depression } \times \text { depression } \\
\text { effect }\end{array}$ & 5.842 & 1 & 5.842 & 0.775 & 0.383 \\
\hline $\begin{array}{l}\text { Depression } \times \text { writing } \\
\text { condition }\end{array}$ & 38.679 & 1 & 38.679 & 6.123 & 0.028 \\
\hline GSI & 93.066 & 1 & 93.066 & 0.928 & 0.34 \\
\hline GSI $\times$ GSI effect & 235.021 & 1 & 235.021 & 2.343 & 0.132 \\
\hline GSI $\times$ writing condition & 335.135 & 1 & 335.135 & 5.232 & 0.03 \\
\hline Social support & 72.948 & 1 & 72.948 & 3.425 & 0.56 \\
\hline $\begin{array}{l}\text { Social support } \times \text { social } \\
\text { support effect }\end{array}$ & 25.615 & 1 & 25.615 & 2.074 & 0.592 \\
\hline $\begin{array}{l}\text { Social } \\
\text { support } \times \text { writing } \\
\text { condition }\end{array}$ & 2.33 & 1 & 2.33 & 0.116 & 0.735 \\
\hline Resilience & 0.928 & 1 & 0.928 & 0.116 & 0.735 \\
\hline $\begin{array}{l}\text { Resilience } \times \text { resilience } \\
\text { effect }\end{array}$ & 2.716 & 1 & 2.716 & 0.338 & 0.563 \\
\hline $\begin{array}{l}\text { Resilience } \times \text { writing } \\
\text { condition }\end{array}$ & 0.965 & 1 & 0.965 & 0.12 & 0.73 \\
\hline
\end{tabular}

is predicted by marital status with higher improvement in not married participants.

\section{DISCUSSION}

The aims of the study were to evaluate the psychological adjustment of Italian HCWs during the COVID-19 pandemic and to investigate the efficacy of an EW intervention to improve their mental well-being. The effects variability in function of individual differences was also investigated.
As regards the first aim, our findings mirror the trend in previous studies on the psychological impact of the COVID-19 affection among the general population in China during its initial stages (Kang et al., 2020; Li et al., 2020; Wang et al., 2020). Specifically, high level of global distress, with severe symptom of somatization, anxiety, obsessive compulsive disorder, sleep disturbances, and specific post-traumatic reactions (reexperiencing, avoidance, and hyperarousal) were found in our sample. Results confirm data from previous pandemics that underlined how HCWs might experience acute stress reactions, particularly after quarantine, developing symptoms of post-traumatic stress disorder, depression, and anxiety (Gold, 2020; Kinman et al., 2020; Pappa et al., 2020). Previous researches had found that psychosomatic symptoms (such as somatization) could accompany specific physical manifestations of various diseases, due to the psychological sequelae of the pandemic outbreaks (Chew et al., 2020; Xiang et al., 2020).

It is widely recognized that HCWs are need of psychological support interventions to help them to mitigate the effects of the COVID-19 pandemic on their well-being in short and long time. In particular, they are in need of recognizing and elaborating emotional stress and pain in order to avoid that unelaborated pain can become chronic and cumulative, with important personal and professional implications (Kinman et al., 2020).

For what is concerned to the second study hypothesis, our data confirm the efficacy of EW, in promoting the reflection upon stressful events and the elaboration of negative feelings that may over the time overwhelm the person's ability to cope with emotional distress, according to previous research (Tonarelli et al., 2017). A significant reduction in several symptoms were found in EW group, while NW group did not show improvement or even presented increased scores in clinical dimensions, maybe due to the continuation of the stress associated with the emergency.

In particular, the study results support the hypothesis that focusing on emotions, feelings, and deeper thoughts allow HCWs to reduce various distress symptoms, such as ptsd symptoms. It impacts positively also on depression symptoms and global psychopathology according to the previous researches 
TABLE 5 | Multiple regression analyses in EW group ( $\Delta$ values as "dependent variables"; age, gender, marital status, and baseline value as "predictors").

\begin{tabular}{|c|c|c|c|c|c|}
\hline Criterion & Predictors & $\beta$ & $T$ & Significant & $R$-square \\
\hline \multirow[t]{4}{*}{$\Delta$ ptsd symptoms } & Age & -0.124 & -0.717 & 0.48 & 0.261 \\
\hline & Gender & -0.3 & -1.69 & 0.103 & \\
\hline & Marital status & 0.444 & 2.531 & 0.018 & \\
\hline & ptsd t1 & 0.163 & 1.938 & 0.047 & \\
\hline \multirow[t]{4}{*}{$\Delta$ depression symptoms } & Age & -0.355 & -2.179 & 0.039 & 0.375 \\
\hline & Gender & -0.322 & -1.938 & 0.064 & \\
\hline & Marital status & 0.439 & 2.66 & 0.013 & \\
\hline & Depression t1 & 0.068 & 0.417 & 0.681 & \\
\hline \multirow[t]{4}{*}{$\Delta \mathrm{GSI}$} & Age & -0.432 & -2.65 & 0.014 & 0.355 \\
\hline & Gender & -0.374 & -2.205 & 0.037 & \\
\hline & Marital status & 0.257 & 1.566 & 0.013 & \\
\hline & GSI t1 & -0.363 & -2.17 & 0.04 & \\
\hline \multirow[t]{4}{*}{$\Delta$ social support } & Age & -0.069 & -0.994 & 0.33 & 0.884 \\
\hline & Gender & 0.148 & 2.113 & 0.045 & \\
\hline & Marital status & -0.215 & -2.637 & 0.014 & \\
\hline & Social support t1 & -1.024 & -12.712 & 0.0001 & \\
\hline \multirow[t]{4}{*}{$\Delta$ resilience } & Age & 0.242 & 1.455 & 0.158 & 0.316 \\
\hline & Gender & 0.015 & 0.086 & 0.932 & \\
\hline & Marital status & -0.515 & -3.015 & 0.006 & \\
\hline & Resilience t1 & 0.216 & 1.22 & 0.234 & \\
\hline
\end{tabular}

(Greenberg et al., 1996; Schoutrop et al., 1997, 2002; Sloan and Marx, 2004a,b).

As regard the third hypothesis, regression analysis showed the moderating role of individual differences in EW benefits. Previous researchers have, in fact, explored different individual variables to identify subgroups for whom EW is more beneficial (Lu and Stanton, 2010). In this study, baseline value of ptsd symptoms predicts the change in post intervention scores: participants who reported more severe symptoms before the writing showed higher benefits, according to previous research (Di Blasio et al., 2015). It should be noted that since the HCWs in this study were part of a normative group, the ptsd, depression, and global psychopathology's symptoms do not have clinical significance but indicate sub-clinical symptoms. Because some research (Brugha et al., 2011; Furukawa et al., 2012) noted that without intervention sub-clinical symptoms tend to increase, the results suggested that the EW intervention in the normative group could be useful to buffer the negative development of psychological distress.

Gender effects were also found in this study, with men showing higher benefits in global psychopathology symptoms and women presenting higher level of perceived social support after EW.

Previous research has underlined gender differences in EW efficacy, but the results are still inconsistent. Some authors stated that men showed higher benefits, but other studies found no difference in outcomes between men and women, and among the studies that did, there is nearly an equal number supporting the argument that the benefits are stronger for women (Stickney, 2010). For example, Smyth et al.'s (1999) meta-analysis suggested that studies with a higher percentage of men had larger effect sizes (i.e., better outcomes) than studies with more women, but Frattaroli's (2006) found no such effect.

Our findings suggested that EW's efficacy in reducing psychopathological symptoms is higher in men. According to Range and Jenkins (2010), we suppose that men tend more to inhibit emotional expression and, when they are "forced" to focus on emotions and feelings, they benefit more than women, who are more used to expressing and verbalizing emotions. On the contrary women showed increased scores in perceived social support after writing and we presume that it's because when women are asked to communicate about negative emotion and thoughts, they perceived the task as and index of closeness and support.

Finally, marital status and age resulted to predict changes in outcome variables, with younger and married participants showing higher benefits, except for social support and resilience that increased more in single people. Authors of previous studies suggested that staff who were younger (Nickell et al., 2004; Sim et al., 2004; Tam et al., 2004; Wu et al., 2009; Austria-Corrales et al., 2011), or parents of dependent children (Maunder et al., 2004; Koh et al., 2005) are more vulnerable to psychological distress, probably because they are afraid of bringing the virus to their home and, in addition, they do not want their families to worry about them (Chen et al., 2020). HCWs may also feel the inner conflict between their desire to care for patients and, at the same time, their need to protect themselves and their loved ones from the life-threatening infection (Kisely et al., 2020).

On the contrary, higher improvements in perceived social support and in resilience in not married participant were found. We presume that single participants could have less opportunity to communicate their inner feeling during the crisis, so they could benefit more from the procedure because they live the research 
like an opportunity to report and reflect on their feelings and negative emotion.

\section{CONCLUSION}

In conclusion, although psychological distress in HCWs is common in situations where they are under pressure to care many potentially infectious patients, EW can help to mitigate it. This kind of intervention could maximize the internal resources of HCWs by effectively improving their quality of life and, consequently, also patient outcomes. The development of a coherent narrative could help them to reorganize and elaborate the traumatic memories, allowing the structuration of more adaptive internal schemas.

The strength of the EW is the rapidity with which it allows the remission of symptoms and the expression of feelings. However, the impact of individual differences highlights the need to accompany this tool with long-term intervention, which could also benefit those who need a deeper elaboration of negative emotion.

The results are interesting but there is some limitation. The most important study limitation is the small sample size, which limited the statistical power of tests and restricts the generalization of results. For that we analyzed in hypothesis 2 and 3 only total score of global dimensions (ptsd symptoms, depression symptoms, GSI, social support, and resilience) but it could be interesting to consider all the sub-symptoms to deeply understand the effect of distress.

In addition, lack a follow-up testing after a longer period (6-12 months) that could allow to better understand if the

\section{REFERENCES}

Austria-Corrales, F., Cruz-Valdés, B., Herrera-Kiengelher, L., Vázquez-García, J. C., and Salas-Hernández, J. (2011). Burnout syndrome among medical residents during the influenza A H1N1 sanitary contigency in Mexico. Gac. Med. Méx. $147,97-103$.

Baikie, K. A. (2003). Rewriting Trauma: How and for Whom Does the Writing Paradigm Work? Doctoral dissertation, Macquarie University, Sydney, NSW.

Baikie, K. A., and Wilhelm, K. (2005). Emotional and physical health benefits of expressive writing. Adv. Psychiatric Treat. 11, 338-346. doi: 10.1192/apt.11.5. 338

Beck, A. T., Steer, R. A., and Brown, G. (1996). Beck Depression Inventory(BDI-II), 2nd Edn. San Antonio, TX: Psychological Corporation.

Brugha, T. S., Morrell, C. J., Slade, P., and Walters, S. J. (2011). Universal prevention of depression in women postnatally: cluster randomized trial evidence in primary care. Psychol. Med. 41, 739-748. doi: 10.1017/S0033291710001467

Chen, Q., Liang, M., Li, Y., Guo, J., Fei, D., Wang, L., et al. (2020). Mental health care for medical staff in China during the COVID-19 outbreak. Lancet Psychiatry 7, e15-e16. doi: 10.1016/S2215-0366(20)30078-X

Chew, N. W. S., Lee, G. K. H., Tan, B. Y. Q., Jing, M., Goh, Y., Ngiam, N. J. H., et al. (2020). A multinational, multicentre study on the psychological outcomes and associated physical symptoms amongst healthcare workers during COVID19 outbreak. Brain Behav. Immun. 20, 30523-30527. doi: 10.1016/j.bbi.2020.04. 049

Derogatis, L. R. (1994). SCL-90-R Symptom Checklist 90 Revised. Minneapolis, MN: NCS Pearson.

Di Blasio, P., Camisasca, E., Caravita, S., and Ionio, C. (2015). The effects of expressive writing on postpartum depression and posttraumatic stress symptoms. Psychol. Rep. 117, 856-882. doi: 10.2466/02.13.PR0.117c29z3 changes in psychological adjustment are consistent and stable during the time.

Finally, to better understand the process of elaboration allowed by the writing intervention, the quantitative analysis could be successfully accompanied by a qualitative analysis of the writing to identify the emotional changes, the narrative markers of the inner process of meaning making, to detect the coping strategies and the changes of thematic content across 3 days (Tonarelli et al., 2017).

\section{DATA AVAILABILITY STATEMENT}

The raw data supporting the conclusions of this article will be made available by the authors, without undue reservation.

\section{ETHICS STATEMENT}

The studies involving human participants were reviewed and approved by the E Campus University Ethic Committee. The patients/participants provided their written informed consent to participate in this study.

\section{AUTHOR CONTRIBUTIONS}

All authors listed have made a substantial, direct and intellectual contribution to the work, and approved it for publication.

Di Fabio, A., and Busoni, L. (2008). Misurare il supporto sociale percepito: proprietà psicometriche della multidimensional scale of perceived social support (MSPSS) in un campione di studenti universitari. Risorsa Uomo 14, $339-350$.

Frattaroli, J. (2006). Experimental disclosure and its moderators: a meta-analysis. Psychol. Bull. 132, 823-856. doi: 10.1037/0033-2909.132.6.823

Friborg, O., Hjemdal, O., Rosenvinge, J. H., and Martinussen, M. (2003). A new rating scale for adult resilience: what are the central protective resources behind healthy adjustment? Int. J. Methods Psychiatr. Res. 12, 65-76. doi: 10.1002/mpr. 143

Frisina, P. G., Borod, J. C., and Lepore, S. J. (2004). A meta-analysis of the effects of written emotional disclosure on the health outcomes in clinical populations. J. Nerv. Ment. Dis. 192, 629-634. doi: 10.1097/01.nmd.0000138317.30764.63

Furukawa, T. A., Horikoshi, M., Kawakami, N., Kadota, M., Sasaki, M., Sekiya, Y., et al. (2012). Telephone cognitive-behavioral therapy for subthreshold depression and presenteeism in workplace: a randomized controlled trial. PLoS One 7:e35330. doi: 10.1371/journal.pone.0035330

Ghisi, M., Flebus, G. B., Montano, A., Sanavio, E., and Sica, C. (2006). Beck Depression Inventory-Second Edition. Adattamento italiano: Manuale. Florence: O-S Organizzazioni Speciali.

Gold, J. A. (2020). Covid-19: adverse mental health outcomes for healthcare workers. BMJ 369:m1815. doi: 10.1136/bmj.m1815

Greenberg, M. A., Wortman, C. B., and Stone, A. A. (1996). Emotional expression and physical health: revising traumatic memories or fostering self-regulation? J. Pers. Soc. Psychol. 71, 588-602. doi: 10.1037/0022-3514.71.3.588

Kang, L., Ma, S., Chen, M., Yang, J., Wang, Y., Li, R., et al. (2020). Impact on mental health and perceptions of psychological care among medical and nursing staff in Wuhan during the 2019 novel coronavirus disease outbreak: a cross-sectional study. Brain Behav. Immun. 87, 11-17. doi: 10.1016/j.bbi.2020.03.028 
King, L. A., King, D. W., Leskin, G., and Foy, D. W. (1995). The Los Angeles symptom checklist: a self report measure of posttraumatic stress disorder. Assessment 2, 1-17. doi: 10.1177/1073191195002001001

Kinman, G., Teoh, K., and Harriss, A. (2020). Supporting the well-being of healthcare workers during and after COVID-19. Occup. Med. (Lond.) 70, 294-296. doi: 10.1093/occmed/kqaa096

Kisely, S., Warren, N., McMahon, L., Dalais, C., Henry, I., and Siskind, D. (2020). Occurrence, prevention, and management of the psychological effects of emerging virus outbreaks on healthcare workers: rapid review and metaanalysis. BMJ 369:m1642. doi: 10.1136/bmj.m1642

Knaak, S., Mantler, E., and Szeto, A. (2017). Mental illness-related stigma in healthcare: barriers to access and care and evidence-based solutions. Healthc. Manage. Forum 30, 111-116. doi: 10.1177/0840470416679413

Koh, D., Lim, M. K., Chia, S. E., Ko, S. M., Qian, F., Ng, V., et al. (2005). Risk perception and impact of severe acute respiratory syndrome (sars) on work and personal lives of healthcare workers in Singapore what can we learn? Med. Care 43, 676-682. doi: 10.1097/01.mlr.0000167181.36730.cc

Li, Z., Ge, J., Yang, M., Feng, J., Qiao, M., Jiang, R., et al. (2020). Vicarious traumatization in the general public, members, and non-members of medical teams aiding in COVID-19 control. Brain Behav. Immun. 88, 916-919. doi: 10.1016/j.bbi.2020.03.007

Lu, Q., and Stanton, A. L. (2010). How benefits of expressive writing vary as a function of writing instructions, ethnicity and ambivalence over emotional expression. Psychol. Health 25, 669-684. doi: 10.1080/08870440902883196

Maunder, R. G., Lancee, W. J., Rourke, S., Hunter, J. J., Goldbloom, D., and Balderson, K. (2004). Factors associated with the psychological impact of severe acute respiratory syndrome on nurses and other hospital workers in Toronto. Psychosom. Med. 66, 938-942. doi: 10.1097/01.psy.0000145673.84698.18

Nickell, L. A., Crighton, E. J., Tracy, C. S., Al-Enazy, H., Bolaji, Y., and Hanjrah, S. (2004). Psychosocial effects of SARS on hospital staff: survey of a large tertiary care institution. CMAJ 170, 793-798. doi: 10.1503/cmaj.1031077

Paez, D., Velasco, C., and Gonzalez, J. L. (1999). Expressive writing and the role of alexithymia as a dispositional deficit in self-disclosure and psychological health. J. Pers. Soc. Psychol. 77, 630-641. doi: 10.1037/0022-3514.77.3.630

Pappa, S., Nella, V., Giannakas, T., Giannakoulis, V. G., Papoutsi, E., and Katsaounou, P. (2020). Prevalence of depression, anxiety, and insomnia among healthcare workers during the COVID-19 pandemic: a systematic review and meta-analysis. Brain. Behav. Immun. 88, 901-907. doi: 10.1016/j.bbi.2020.05. 026

Pennebaker, J. W. (1997). Writing about emotional experiences as a therapeutic process. Psychol. Sci. 8, 162-166. doi: 10.1111/j.1467-9280.1997.tb00403.x

Pennebaker, J. W. (2004). Theories, therapies, and taxpayers: on the complexities of the expressive writing paradigm. Clin. Psychol. Sci. Pract. 11, 138-142. doi: 10.1093/clipsy.bph063

Pennebaker, J. W., and Beall, S. K. (1986). Confronting a traumatic event: toward an understanding of inhibition and disease. J. Abnorm. Psychol. 95, 274-281. doi: 10.1037//0021-843x.95.3.274

Pennebaker, J. W., and Chung, C. K. (2007). "Expressive writing, emotional upheavals, and health," in Foundations of Health Psychology, eds H. S. Friedman and R. C. Silver (Oxford: Oxford University Press), 263-284.

Pennebaker, J. W., and Francis, M. E. (1996). Cognitive, emotional, and language processes in disclosure. Cogn. Emot. 10, 601-626. doi: 10.1080/ 026999396380079

Peterson, R. A. (1994). A meta-analysis of Cronbach's coefficient alpha. J. Consum. Res. 21, 381-391. doi: 10.1086/209405

Polizzi, C., Lynn, S. J., and Perry, A. (2020). Stress and coping in the time of covid-19: pathways to resilience and recovery. Clin. Neuropsychiatry 17, 59-62. doi: 10.36131/CN20200204

Preti, E., Di Mattei, V., Perego, G., Ferrari, F., Mazzetti, M., Taranto, P., et al. (2020). The psychological impact of epidemic and pandemic outbreaks on healthcare workers: rapid review of the evidence. Curr. Psychiatry Rep. 22:43. doi: 10.1007/s11920-020-01166-z

Prezza, M., and Principato, M. C. (2002). "La rete sociale e il sostegno sociale," in Conoscere la Comunità, eds M. Prezza and M. Santinello (Bologna: Il Mulino), 193-234.

Prunas, A., Sarno, I., Preti, E., Madeddu, F., and Perugini, M. (2012). Psychometric properties of the Italian version of the SCL-90-R: a study on a large community sample. Eur. Psychiatry 27, 591-597. doi: 10.1016/j.eurpsy.2010. 12.006

Range, L. M., and Jenkins, S. R. (2010). Who benefits from Pennebaker's expressive writing paradigm? Research recommendations from three gender theories. Sex Roles 63, 149-164. doi: 10.1007/s11199-010-9749-7

Schoutrop, M. J. A., Lange, A., Brosschot, J., and Everaerd, W. (1997). “Overcoming traumatic events by means of writing assignments," in The (Non) Expression of Emotions in Health and Disease, eds A. Vingerhoets and F. J. J. van Bussel (Tilburg: Tilburg University Press), 279-289.

Schoutrop, M. J. A., Lange, A., and Hanewald, G. (2002). Structured writing and processing major stressful events: a controlled trial. Psychother. Psychosom. 71, 151-157. doi: 10.1159/000056282

Serafini, G., Parmigiani, B., Amerio, A., Aguglia, A., Sher, L., and Amore, M. (2020). The psychological impact of COVID-19 on the mental health in the general population. QJM 113, 531-537. doi: 10.1093/qjmed/hcaa201

Sexton, J. D., Pennebaker, J. W., Holzmueller, C. G., Wu, A. W., Berenholtz, S. M., Swoboda, S. M., et al. (2009). Care for the caregiver: benefits of expressive writing for nurses in the United States. Prog. Palliat. Care 17, 307-312. doi: 10.1179/096992609X12455871937620

Sim, K., Chong, P. N., Chan, Y. H., and Soon, W. S. (2004). Severe acute respiratory syndrome-related psychiatric and posttraumatic morbidities and coping responses in medical staff within a primary health care setting in Singapore. J. Clin. Psychiatry 65, 1120-1127. doi: 10.4088/JCP.v65n 0815

Sloan, D. M., and Marx, B. P. (2004a). A closer examination of the structured written disclosure procedure. J. Consult. Clin. Psychol. 72, 165-175. doi: 10.1037/0022-006X. 72.2.165

Sloan, D. M., and Marx, B. P. (2004b). Taking pen to hand: evaluating theories underlying the written disclosure paradigm. Clin. Psychol. 11, 121-137. doi: 10.1093/clipsy.bph062

Sloan, D. M., Marx, B. P., and Epstein, E. M. (2005). Further examination of the exposure model underlying the efficacy of written emotional disclosure. J. Consult. Clin. Psychol. 73, 549-554. doi: 10.1037/0022-006X.73.3.549

Sloan, D. M., Marx, B. P., Epstein, E. M., and Lexington, J. M. (2007). Does altering the writing instructions influence outcome associated with written disclosure? Behav. Ther. 38, 155-168. doi: 10.1016/j.beth.2006.06.005

Smyth, J. M. (1998). Written emotional expression: effect sizes, outcome types, and moderating variables. J. Consult. Clin. Psychol. 66, 174-184. doi: 10.1037/0022006X.66.1.174

Smyth, J. M., Stone, A. A., Hurewitz, A., and Kaell, A. (1999). Effects of writing about stressful experiences on symptom reduction in patients with asthma or rheumatoid arthritis. J. Am. Med. Assoc. 281, 1304-1309. doi: 10.1001/jama.281. 14.1304

Solano, L., Donati, V., Pecci, F., Persichetti, S., and Colaci, A. (2003). Postoperative course after papilloma resection: effects of written disclosure on the experience in subjects with different alexithymia levels. Psychosom. Med. 65, 477-484. doi: 10.1097/01.psy.0000035781. $74170 . \mathrm{f1}$

Stickney, L. T. (2010). Who benefits from Pennebaker's expressive writing? More research recommendations: a commentary on Range and Jenkins. Sex Roles 63, 165-172. doi: 10.1007/s11199-010-9771-9

Tam, C. W., Pang, E. P., Lam, L. C., and Chiu, H. F. (2004). Severe acute respiratory syndrome (SARS) in Hong Kong in 2003: stress and psychological impact among frontline healthcare workers. Psychol. Med. 34, 1197-1204. doi: 10.1017/ S0033291704002247

Tonarelli, A., Cosentino, C., Artioli, D., Borciani, S., Camurri, E., and Colombo, B. (2017). Expressive writing. A tool to help health workers. Research project on the benefits of expressive writing. Acta Biomed. 88, 13-21.

Vrij, A., Nunkoosing, K., Paterson, B., Oosterwegel, A., and Soukara, S. (2002). Characteristics of secrets and the frequency, reasons and effects of secrets keeping and disclosure. J. Community Appl. Soc. Psychol. 12, 56-70. doi: 10. 1002/casp.652

Wang, C., Pan, R., Wan, X., Tan, Y., Xu, L., Ho, C. S., et al. (2020). Immediate psychological responses and associated factors during the initial stage of the 2019 coronavirus disease (COVID-19) epidemic among the general 
population in China. Int. J. Environ. Res. Public Health 17:1729. doi: 10.3390/ ijerph17051729

West, C. P., Dyrbye, L. N., and Shanafelt, T. D. (2018). Physician burnout: contributors, consequences and solutions. J. Intern. Med. 283, 516-529. doi: 10.1111/joim.12752

World Health Organization (WHO) (2020). Coronavirus Disease 2019 (COVID19) Situation Report-82. Available online at: https://www.who.int/directorgeneral/speeches/detail/who-director-general-s-opening-remarks-at-themedia-briefing-on-covid-19---11-march-2020

Wu, P., Fang, Y., Guan, Z., Fan, B., Kong, J., and Yao, Z. (2009). The psychological impact of the SARS epidemic on hospital employees in China: exposure, risk perception, and altruistic acceptance of risk. Can. J. Psychiatry 54, 302-311. doi: 10.1177/070674370905400504

Xiang, Y. T., Yang, Y., Li, W., Zhang, L., Zhang, Q., Cheung, T., et al. (2020). Timely mental health care for the 2019 novel coronavirus outbreak is urgently needed. Lancet Psychiatry 7, 228-229. doi: 10.1016/S2215-0366(20)3 0046-8
Yang, L., Yin, J., Wang, D., Rahman, A., and Li, X. (2020). Urgent need to develop evidence-based self-help interventions for mental health of healthcare workers in COVID-19 pandemic. Psychol. Med 1-2. doi: 10.1017/S0033291720001385

Zimet, G. D., Dahlem, N. W., Zimet, S. G., and Farley, G. K. (1988). The multidimensional scale of perceived social support. J. Pers. Assess. 52, 30-41. doi: 10.1207/s15327752jpa5201_2

Conflict of Interest: The authors declare that the research was conducted in the absence of any commercial or financial relationships that could be construed as a potential conflict of interest.

Copyright (c) 2021 Procaccia, Segre, Tamanza and Manzoni. This is an open-access article distributed under the terms of the Creative Commons Attribution License (CC BY). The use, distribution or reproduction in other forums is permitted, provided the original author(s) and the copyright owner(s) are credited and that the original publication in this journal is cited, in accordance with accepted academic practice. No use, distribution or reproduction is permitted which does not comply with these terms. 